\title{
FEATURES OF HERITAGE BIM MODELING BASED ON LASER SCANNING DATA
}

\author{
Julia Gorkovchuk $^{1}$, Denys Gorkovchuk ${ }^{1}$ \\ ${ }^{1}$ Kyiv National University of Construction and Architecture, Ukraine - kravchenko.iuv@knuba.edu.ua
}

Commission V, WG V/7

KEY WORDS: BIM, laser scanning, culture heritage

\begin{abstract}
:
BIM modeling technologies are gradually becoming mandatory and necessary in a life cycle of a building or structure. The main difference between BIM and other types of design is the collection and comprehensive processing of all architectural, technological, economic, operational and other information about the building in a single informational environment. Moreover, all elements of the model are interconnected and interdependent, which ensures the maximum proximity of the model to the real situation. The advantages of BIM technology for cultural heritage sites are operational guidance and quality control of restoration and construction works, minimizing the probability of errors in projects, cost reduction and optimization at operation phase. Technological scheme of highprecision information modeling of cultural heritage objects includes data acquisition, modelling of structural elements and accumulation of attributive information in a specialized software environment, quality control, visualization. The data acquisition stage is based on analysis of existing data and documentation, executive surveys. For this purpose, terrestrial laser scanning is a perfect surveying tool due to its speed, accuracy, completeness of data and level of detail. The difficulty of determining the technical characteristics of the elements and their physical properties, can be partially solved with excessive information provided from laser scanning, and the complexity of modeling deformations and deviations, restricts the level of development and detail (LOD) of the BIM model but define use of mixed LOD (LOD200-500) for a cultural heritage object. The factors that determine the LOD of BIM modeling are: the current state of the object, surveying accessibility, availability of documentation etc. Considering such modeling features provides the creation of a informational model that determines the functionality of the object, in respect with its cultural, historical and architectural value.
\end{abstract}

\section{INTRODUCTION}

\subsection{BIM and LOD}

Building Information Modeling (BIM) is a digital representation of the physical and functional characteristics of an object that creates a shared information resource of the object and forms a solid basis for decision-making throughout its life cycle: from early concepts to disposal (Standards USA, 2014). The main difference between BIM and other types of modeling is the collection and comprehensive processing of all architectural, technological, economic, operational and other information about the building in a single information environment. In this case, all elements of the model are interconnected and interdependent, which ensures maximum proximity of the model to the real situation.

Building Information Models - a set of structured and unstructured information containers (data sets) within a single information system that contains the necessary geometric, physical, functional and other characteristics of the object, which are the source for the documentation accompanying the life cycle of the object (design documentation, estimates, operating instructions, etc.) (British Standards Institution, 2019).

The main characteristic of BIM is the level of development (LOD), which determines how much graphic and non-graphic (attributive) information is required for a particular element of the information model at a certain stage of its development. To ensure the organization of BIM project planning, 3D coordination and transfer of the necessary information, there are 6 basic LODs defined in Level of Development specification by (BIM Forum, 2021): LOD100, LOD200, LOD300, LOD350, LOD400 and LOD500.

It is worth noting that full implementation of LOD higher than 300 is possible only for objects, which are fully designed and constructed with BIM approach. For this purpose, architects and designers use libraries or families of elements developed in LOD 400 (which can be provided by the manufacturers of these elements) or create them by specifying the detailed information needed to manufacture such elements. The possibilities for obtaining such information for existing facilities are usually very limited.

In turn, the LOD500, which in addition to the LOD400 should contain information about the actual size and location of the elements of the constructed object, today is rather conceptual, as no BIM software allows to accurately represent all building elements with all possible deformations.

\subsection{BIM modelling for existing building}

Today's national and industry standards (link) transparently and clearly regulate the use of BIM technology in the design, construction and operation of new projects. The issue of implementing information modeling for existing buildings and structures is considered only in the context of a particular cases when highlighting the features of the reconstruction or operation of unique facilities. For example, implementation of BIM in the reconstruction of the Sydney Opera House (Schevers and etc, 2007), Notre-Dame de Paris Cathedral (Day M., 2021), Torrelobatón Castle in Spain (Martín-Lerones end etc., 2021), Wisla Football Stadium in Krakow, Poland (Talapov, 2014), Denver Airport, USA (Denver's Airport Expansion primes a push toward BIM, 2017).

Typically, the implementation of BIM approach for existing buildings and structures occurs during their reconstruction together with the design of new utilities and equipment in accordance with modern requirements. Accordingly, the following tasks arise in the process:

1) recovering of lost technical documentation; 
2) conversion of existing 2D-documentation (drawings) into BIM-format;

3) updating existing BIM model from executive surveys;

4) new BIM modelling from executive surveys;

5) implementation of automated real estate management systems

The modeling stage becomes the initial stage of BIM approach and consists in high-precision representation of changes in architectural structures. At this stage, the first difficulties of BIM implementation for existing buildings and structures arise, in particular:

1) Limitation of the level of development and level of detail information about the internal structure of the elements usually is very limited or absent, which makes modeling very complicated in LOD above 300;

2) the complexity of modeling objects that have deformations or deviations - most modern BIM software have no options for modeling deviations, such as deformation or damages of structural elements;

3) limitation of the BIM model by architectural components most of the structural load-bearing elements of buildings are closed with a finishing and it is not possible to obtain information about such elements.

4) the need to develop libraries (families) of elements manufacturers of building materials and structures provide libraries for their new products, but for existing facilities that were built many years ago, such libraries do not exist.

Of course, classical data collection methods (geodetic measurements, photogrammetry) are also used in data collection. However, significant advantages in this case have laser scanning technologies, due to its speed, accuracy, completeness of data and level of detail. At the same time, hardware manufacturers are already offering special tools focused on BIM. Examples are the Leica BLK360 ultraportable terrestrial scanner, Leica Pegasus backpack mobile systems or trolleys with a camera system, laser scanner, inertial system and more. Such systems allow you to get a huge array of data in the shortest possible time. The advantages and peculiarities of the Scan to BIM approach can be assessed by analyzing examples of applications to the solution of applied problems, including the modeling of cultural heritage sites (Pepe $\mathrm{M}$ and etc, 2021).

\subsection{The current state of use BIM technologies for in cultural heritage}

The urgency and relevancy of BIM implementation for cultural heritage objects is defined by the need of constant monitoring of the current state of the building in order to apply preservation and restoration measures in a correct time.

Considering the high value of such objects there is also high economic demand in proper operation of such objects in various fields, as well as solving management problems based on informatization and automation.

At the end of the 2010s, the term heritage building information modeling H-BIM (López, F.L and etc, 2018) emerged, which is the basis for the development of modern approaches to highprecision modeling of geometric and semantic properties of cultural heritage sites based on heterogeneous source data. Algorithms for processing point clouds for the needs of BIM are also being improved, in particular, machine learning methods for classifying elements of buildings and structures are proposed (Croce V and etc., 2021).

Obviously, BIM approach is not only a tool for digitizing cultural heritage sites, but also provides opportunities for effective management at all stages of the life cycle, as evidenced by numerous examples of technology implementation in the reconstruction of Sydney Opera House (Schevers and etc, 2007),
Notre-Dame de Paris Cathedral (Day M., 2021), The Papal Basilica of Saint Francis in Assisi in Italy (Angelini and etc., 2017).

A large-scale fire in the Cathedral of Our Lady of Paris raised a serious question about the organization of reconstruction work. Immediately after the fire, the authorities announced a deadline for reconstruction work of 5 years. And almost immediately work on creating a BIM model of the cathedral was started. It is based on laser scanning data of the cathedral obtained several years ago. The resulting model allows to effectively organize the reconstruction work, as well as directly plan for firefighting measures to prevent such events in the future.

\subsection{Objectives}

The aim of the work is to develop a unified approach to information modeling of cultural heritage sites, which takes into account their features in order to ensure the necessary accuracy and detail. Identifying the special aspects of each stage of building information modelling will ensure its effective implementation for unique historical objects. Terrestrial laser scanning was chosen for executive surveys as the most modern approach for obtaining accurate and complete data about the object.

\section{BIM APPROACH}

\subsection{Technological scheme of high-precision information modelling of cultural heritage sites}

Each stage of BIM modelling process for existing buildings has its peculiarities comparing to the general process (Table 1). While in the general approach the collection of geospatial data is necessary only to obtain a digital basis for further modelling, for existing buildings at this stage, executive surveys are carried out to obtain geometric and attributive information about the object. Also, the general approach involves gradual modelling with increasing LOD at each phase, and modelling of existing buildings based on executive surveys is carried out directly with LOD from project specification, and such a model will be partially in LOD500, as these executives reflect elements in their real position.

In both cases, at the first stage, the feasibility study of the project, analysis of customer requirements and analysis of potential constraints that may arise during the project are studied. As a result, a technical specification of the project is developed, which prescribes in detail the required LOD of the BIM model for all elements of the building. According to the priority of the tasks, LOD levels might be mixed or adjusted and not correspond with the standard. Often intermediate LODs (e.g. LOD250) are established to define mix of LOD200 and LOD300 requirements. A BIM Execution plan (BEP) is also being developed, which describes the interaction of all project participants at all stages of its implementation from design to use.

The data collection phase analyzes and integrates all existing data about the object, including 2D drawings, information from geoportals and cadastral sources. Obviously, this information is not enough to create a BIM Model of the object, so the appropriate method of data collection need to be selected. For cultural heritage sites, the most optimal method is terrestrial laser scanning, due to its speed, accuracy and completeness of the data. 


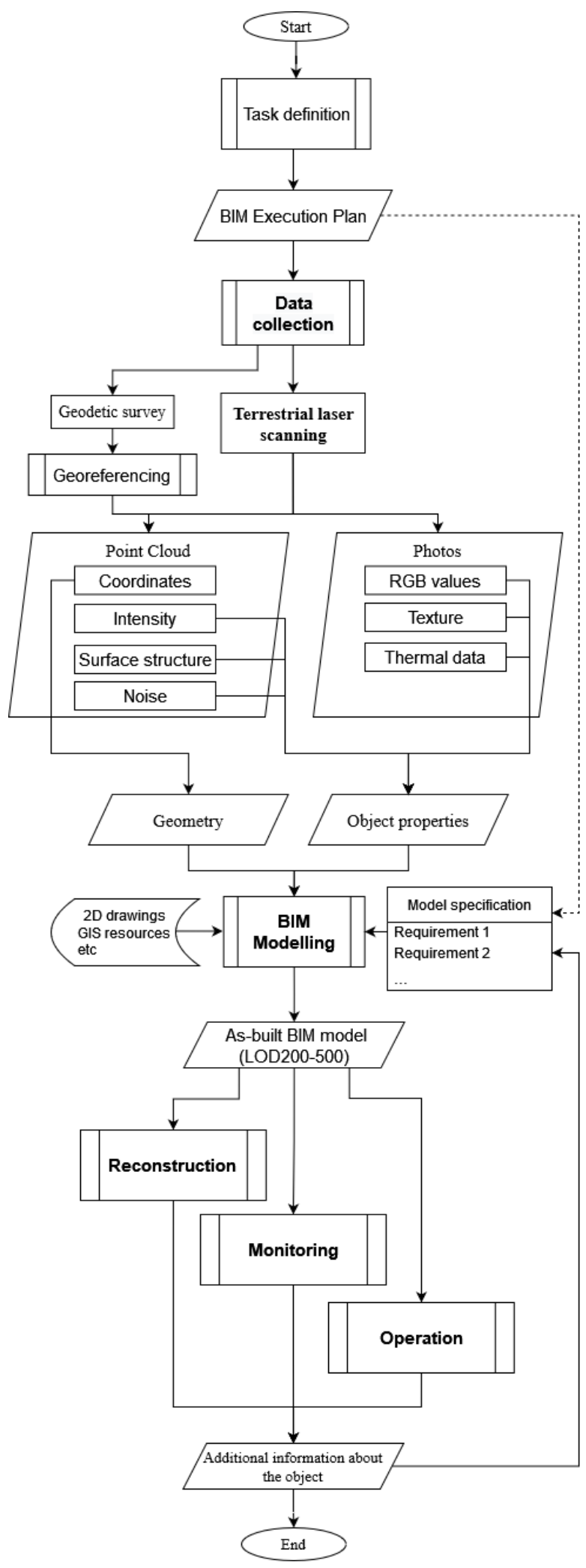

Figure 1. BIM Modelling workflow for cultural heritage objects.

The speed of modern scanners reaches 2 million points per second, which makes it possible in a short time to get a very dense point cloud, which together with the intensity is able to represent the surface structure, and thus identify materials. They can also be equipped with thermal cameras that provide additional information about the properties of objects or their internal structure.

At the next step, all the information obtained is integrated into a single environment and is used for BIM modelling.

During the reconstruction, monitoring and operation of a cultural heritage site, additional information about this site is constantly provided. As a rule, in the process of reconstruction the information on the realized constructive decisions is actualized. The monitoring process involves recording the spatial position of the elements and their condition. During operation, mostly attributive information about the actual use of the building is updated.

\begin{tabular}{|c|c|c|}
\hline Stage & $\begin{array}{c}\text { Generic BIM } \\
\text { Modelling workflow }\end{array}$ & $\begin{array}{c}\text { BIM Modelling of existing } \\
\text { buildings }\end{array}$ \\
\hline 1 & $\begin{array}{l}\text { Task definition: } \\
\text { feasibility study, } \\
\text { analysis of customer } \\
\text { requirements, analysis } \\
\text { of potential constraints }\end{array}$ & \begin{tabular}{l}
\multicolumn{2}{c}{ Task definition: } \\
feasibility study, analysis of \\
customer requirements, \\
analysis of potential \\
constraints
\end{tabular} \\
\hline 2 & $\begin{array}{l}\text { Definition of LOD } \\
\text { requirements } \\
\text { Development of BIM } \\
\text { Execution plan (BEP) }\end{array}$ & $\begin{array}{lll}\begin{array}{l}\text { Definition of } \\
\text { requirements }\end{array} & \text { LOD } \\
\text { Development of } & \text { BIM } \\
\text { Execution plan (BEP) } & \\
\end{array}$ \\
\hline 3 & $\begin{array}{l}\text { Data collection: } \\
\text { - GIS Resources } \\
\text { - Geodetic survey of } \\
\text { build-up area }\end{array}$ & $\begin{array}{l}\quad \text { Data collection: } \\
\text { - Existing 2D drawings } \\
\text { - GIS Resources } \\
\text { - Geodetic survey } \\
\text { - Laser scanning }\end{array}$ \\
\hline 4 & $\begin{array}{l}\text { Modelling: } \\
\text { 1. Pre-design } \\
\text { concept (LOD100) } \\
\text { 2. Design } \\
\text { concept (LOD200) } \\
\text { 3. Detailed } \\
\text { design documentation } \\
\text { and cost estimation } \\
\text { (LOD300) }\end{array}$ & $\begin{array}{l}\text { Modelling: } \\
\text { 1. Modelling of } \\
\text { geometry (LOD250-500) } \\
\text { 2. Filling } \\
\text { attributes }\end{array}$ \\
\hline 5 & $\begin{array}{l}\text { Construction } \\
\text { (LOD400-500): } \\
\quad 1 . \quad \text { Monitoring } \\
\text { (as-built } \\
\text { documentation, } \\
\text { schedules, reports, } \\
\text { quality control) } \\
\quad \text { 2. Changes in } \\
\text { materials and design } \\
\text { solutions }\end{array}$ & $\begin{array}{l}\text { Reconstruction } \\
\text { (LOD400-500): } \\
\text { 1. Monitoring (as- } \\
\text { built documentation, } \\
\text { schedules, reports, quality } \\
\text { control) } \\
\text { 2. Changes in } \\
\text { materials and design } \\
\text { solutions }\end{array}$ \\
\hline 6 & $\begin{array}{l}\text { Building operation } \\
\text { (LOD500): } \\
\text { 1. Complete } \\
\text { information on the } \\
\text { actual condition of } \\
\text { the object is passed to } \\
\text { the property owner } \\
\text { 2. Information } \\
\text { on engineering } \\
\text { networks and their } \\
\text { operation is passed to } \\
\text { service providers } \\
\text { 3. Monitoring }\end{array}$ & $\begin{array}{l}\text { Building operation } \\
\text { (LOD500): } \\
\text { 1. Complete } \\
\text { information on the actual } \\
\text { condition of the object is } \\
\text { passed to the property } \\
\text { owner } \\
\text { 2. Information on } \\
\text { engineering networks and } \\
\text { their operation is passed } \\
\text { to service providers } \\
\text { 3. Monitoring }\end{array}$ \\
\hline
\end{tabular}

Table 1. Comparison of BIM Modelling approaches for general case and for existing buildings 


\subsection{Cultural heritage BIM modelling aspects}

\section{No data}

At present, information on historic buildings and archeological sites is usually presented in the form of separate documents, reports, drawings, computer-aided design files (CAD; 2D or 3D) and various databases provided by individual specialists, each using different tools and standards. Information about one historical object can be located in several places (electronic data warehouses, databases and physical archives) and in different formats (paper and electronic). The status and quality of data in individual sources may be unknown (data may be replaced, uncoordinated or incomplete).

\section{There are already different control systems}

In many cases, there is no single reliable source of complete and reliable information about a cultural heritage site. Organizations dealing with a large number of historic sites, or even the owners and managers of a single site, can use different types of enterprise systems (such as site management system, infrastructure management system, geographic information system) to manage real estate or property information. Such systems should contain coordinated and verified information about objects, but not always be associated with 3D geometry (Brian, 2019). $\mathrm{BIM}$ can be a platform for integrating all data.

\section{CASE STUDIES OF PROPOSED BIM APPROACH FOR CULTURAL HERITAGE OBJECTS}

\subsection{Teacher House, Kyiv, Ukraine.}

Kyiv City Teacher's House (Figure 2), located in the central historical area of the city in Shevchenkivskyi district is nationally significant architectural and historical monument. The building was built in 1910-1912 (designed by the famous architect Pavel Alyoshin) for the needs of the educational community. Today it is a cultural and educational center that promotes the creative and professional growth of educators.

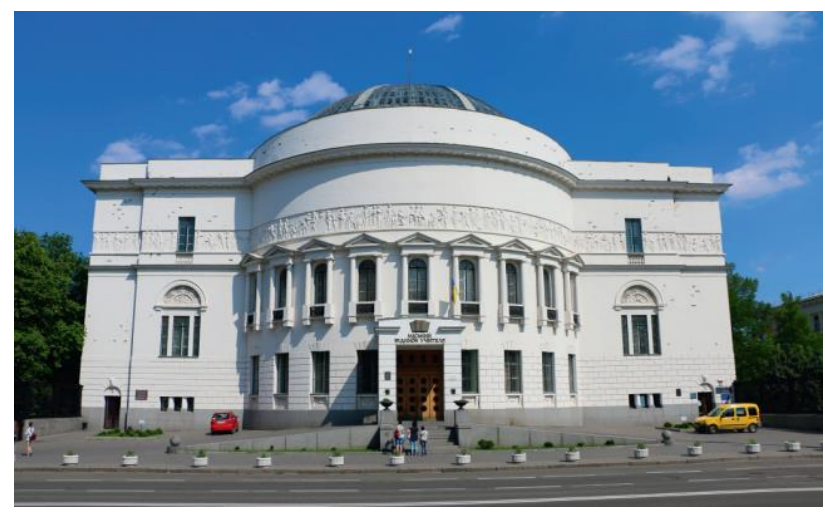

Figure 2. Kyiv Teacher's House front facade

For 107 years of its history, the building has never been restored and, guided by political expediency, has hardly been used for its intended purpose. The actual condition of the building is unusable and requires immediate restoration work.

The peculiarity of the building is that the Museum of the Ukrainian Revolution of 1917-1921, the Pedagogical Museum of Ukraine, the Sukhomlinsky State Scientific and Pedagogical Library, the Kiyanochka Cultural Center, and the Kyiv Trade Union of Education and Science Workers of Ukraine are located in the Teacher's House.

Therefore, with the start of restoration work in 2018, the main approach to the reconstruction project was chosen Information modeling of the building, and terrestrial laser scanning in combination with photogrammetry was choosen as the main method of survey. The main reason for this is the presence of decorative elements that are problematic to capture. Also, considering the large number of damages on the facade that need to be documented to select the optimal method of reconstruction, laser scanning is the only method that can provide the required level of detail and completeness of the data. Additionally, UAV photogrammetric surveys were used to cover hard-to-reach and dangerous areas of the roof and upper facades. Leica P40 was used for scanning and DJI Phantom 3 Pro was used for aerial survey.

To obtain the data in the same geodetic coordinate system common control points, measured by total station were used. All survey data was merged together into single point cloud with 5 $\mathrm{mm}$ resolution on the facades and approx. $10 \mathrm{~mm}$ resolution on the roof (Figure 3).

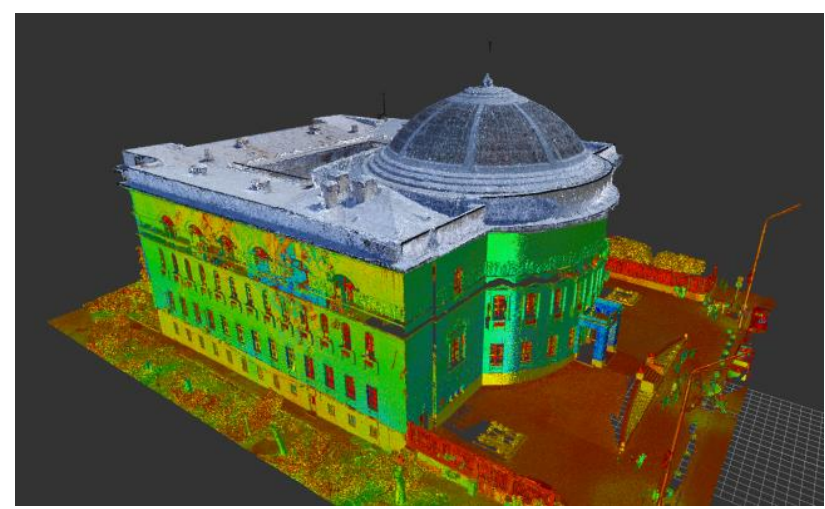

Figure 3. Fusion of TLS and photogrammetry point clouds of Kyiv Teacher's House

Autodesk Revit was chosen as a platform for BIM Modelling. Damages of the facades were the most critical, so at the first step the exterior model in LOD300 was created (Figure 4). For all windows, doors and other repetitive facade elements new families in Revit were created. All of the unique elements (e.g. plastering, bas-relief and sculptures) were modelled as mesh models. Such models consist of millions of polygons and therefore can be hardly integrated into BIM software without loss of performance. To solve this problem such elements were modelled in a separate file and linked to the project as external resource. It allows to quickly unload these elements from the projects when high-detail representation is not required.

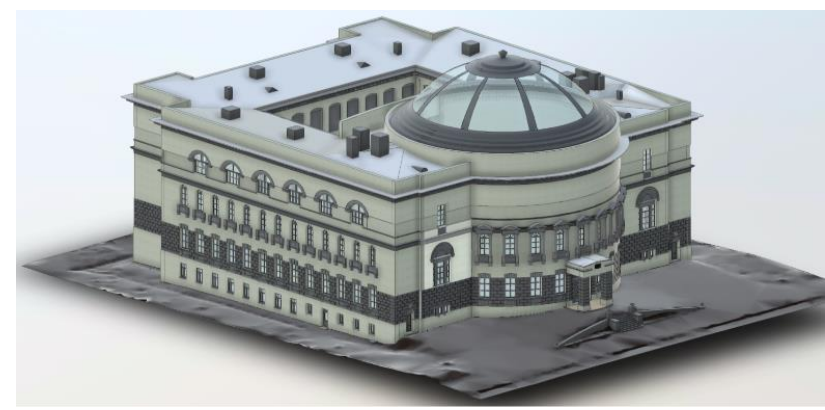

Figure 4. BIM Model of Kyiv Teacher's House

Resulting BIM model was provided to the restoration team. In combination with point cloud precise documentation of damages was developed to create reconstruction plan. Implementation of restoration measures is resulted in immediately changes in BIM Model.

The interior of the building is not as damaged as the facades, so its reconstruction is planned in the second stage. The same 
terrestrial laser scanning survey method is expected to obtain upto-date interior information. But already with integration into the existing BIM Model.

\subsection{Salzmagazin, Stans, Switzerland}

The Salzmagazin (lit. Salt storage house, Figure 5) was originally built to store grain and salt for the community in 1700. It has had many other uses since then including; a theater, a secondary school and finally a museum.

The building is typical example of Swiss "Fachwerk" architecture of that time and except of the ground floor is almost entirely built of wood.

During its existence, the wooden structures of the building have significantly lost their strength and need to be replaced. But due to heritage status of the building it is not allowed to replace it with metal or concrete parts, so the whole building should be reconstructed with the same materials.

BIM approach for reconstruction was chosen as part of the implementation of recent construction laws in Switzerland.

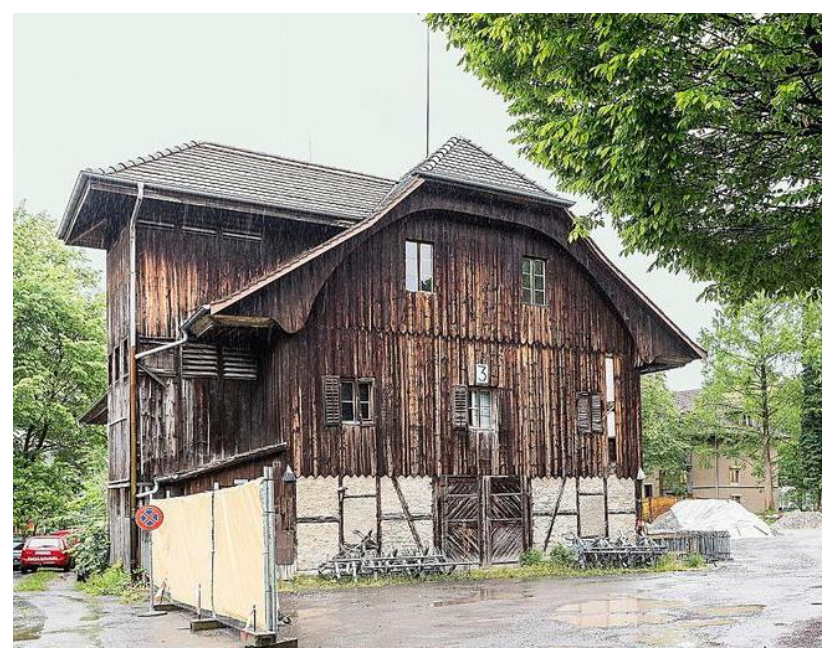

Figure 5. Building of Salzmagazin museum

The complete building was scanned with Faro Focus S350 terrestrial laser scanner (Figure 6). Additionally, photos of the inside and outside were taken.

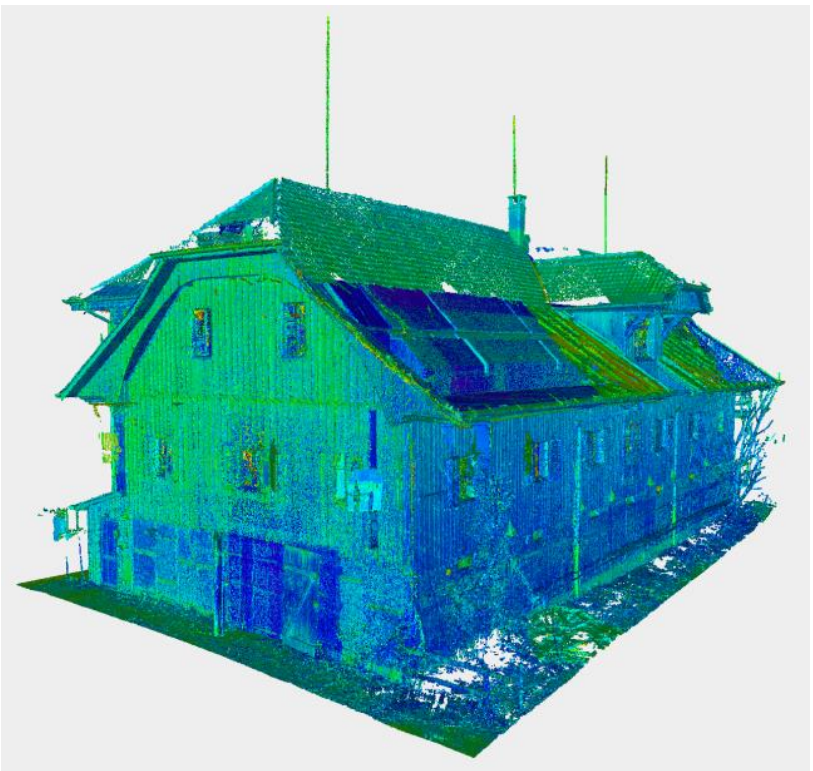

Figure 6. Point cloud of scanned Salzmagazin building
The BIM Execution plan defined the creation of a model with a LOD 300 for building structures and an accuracy of $2 \mathrm{~cm}$.

The features of the building and scan resolution of $2 \mathrm{~mm}$ make it possible to very accurately distinguish and identify structural elements of the building, including their materials. Even the internal structure of the walls is measurable, which makes it possible to implement the LOD400.

Modelling was done in Graphisoft ArchiCAD software. One of the reasons for choosing this software package for this project was the presence of a large library of elements for Switzerland, which includes a large number of typical architectural solutions for this country. It allowed to implement LOD400 model for Salzmagazin building without creating custom libraries (Figure 7).

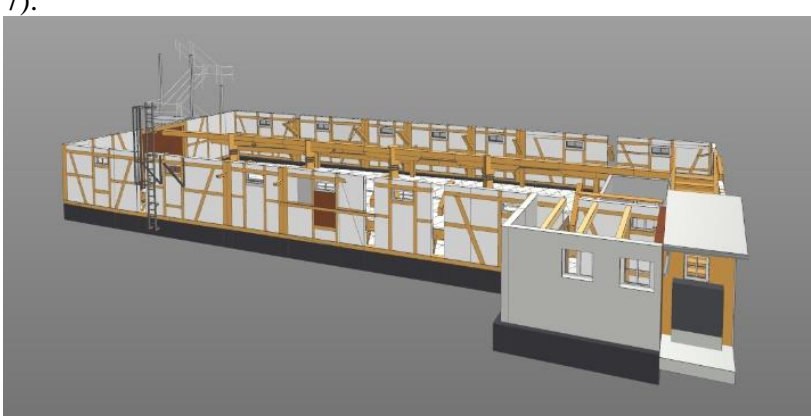

Figure 7. LOD400 BIM Model of the ground level of Salzmagazin in ArchiCAD

ArchiCAD has also very rich functions in modelling of the wooden structures. Custom shaped wooden structures (Figure 8) can be modelled with very high-level of detail, enough for producing such elements.

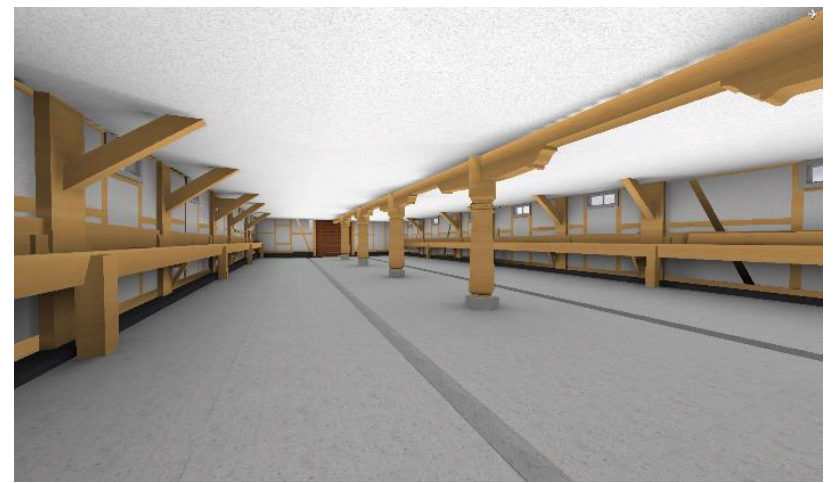

Figure 8. BIM model of the ground level of the building with custom wooden structures.

Additionally, the specifics of wooden element deformations in this project (tilt and offset) allows to model them as-built, which represent LOD500 in geometry (Figure 9).

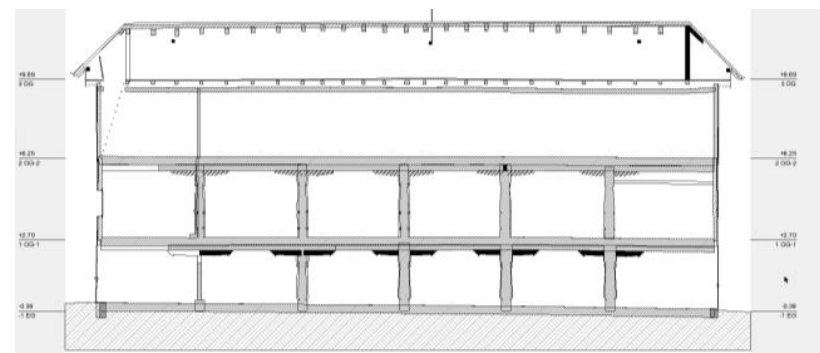

Figure 9. Longitudinal section of the building with visible deformations 
The building model obtained as a result of the BIM approach complied with the LOD500 for all structural elements and reflected the state of the building with $2 \mathrm{~cm}$ accuracy.

One of the advantages of BIM approach is the ability to generate drawings and specifications directly from BIM model and provide it to all parts of building operation process. Detailed drawings of wooden structures were delivered to woodworking companies for producing replacement parts. It is expected to repeat survey of the buildings after finishing the reconstruction process to update the model to actual state.

\section{DISCUSSION}

The considered features of each stage of heritage building information modelling allow to unify approaches for their successful performance. Especially important is the stage of aggregation of input data to achieve the maximum possible level of LOD for the BIM model. The use of modern data collection methods should be combined with existing often outdated data sources.

For historical monuments, it is mandatory to conduct monitoring at various levels, which is part of the stage of operation of the object with the mandatory entry of data in official registers and databases. Implementation of monitoring with reflection of results in the current BIM model will increase its level of detail to LOD500.

But the main difficulty in implementing BIM for cultural heritage sites is the uniqueness of both the site as a whole and its individual elements. Solving this problem still remains the responsibility of the specialist.

\section{CONCLUSION}

The main feature of heritage building information modeling is the need to create a high-precision model of an existing object, which is unique and, as a rule, complex in form, structure, properties, etc. The differences identified for each stage of the technology allow to plan, implement and use BIM for cultural heritage sites efficiently and powerfully. At the data collection stage, all available sources of information, modern engineering research methods and data fusion algorithms should be anticipated and used to improve the input data. The modelling process itself involves selection or creating of proper families of elements for modelling and their correct implementation. The proposed conditional values of the level of detail LOD250 and LOD350 more clearly reflect the real process of BIM modelling of existing buildings and structures. The main and obligatory part of operation stage of a cultural heritage site should be monitoring, whereby the BIM model is updated and use modes of the site are adjusted.

The given examples of realization of heritage building information modeling for Teacher's House in Kyiv and Salzmagazin museum in Stans are realized on the basis of the scan to BIM approach widespread today with adding photogrammetry at data collection stage for obtaining additional attributive information.

\section{FURTHER RESEARCH}

Despite the uniqueness of objects and their elements, each stage of the heritage building information modeling process can be considered as a separate task, the implementation of which should be based on current approaches, such as machine learning, neural networks and other algorithms for data processing automation.

\section{REFERENCES}

Angelini, M. G., Baiocchi, V., Costantino, D., \& Garzia, F. (2017). SCAN TO BIM FOR 3D RECONSTRUCTION OF THE PAPAL BASILICA OF SAINT FRANCIS IN ASSISI IN ITALY. International Archives of the Photogrammetry, Remote Sensing \& Spatial Information Sciences, 42. doi:10.5194/isprsarchives-XLII-5-W1-47-2017

Brian Paul, Antonopoulou Sofia (2019) BIM for Cultural Heritage: Development of an Information Model of a Historic Building. Publishing solutions, 2019. - 106 p. ISBN 978-5-44965142-6.

British Standards Institution (2019) BS EN ISO 19650: Organisation and digitisation of information about buildings and civil engineering works, including building information modelling - Information management using building information modelling, London: BSI

Croce V, Caroti G, De Luca L, Jacquot K, Piemonte A, Véron P. From the Semantic Point Cloud to Heritage-Building Information Modeling: A Semiautomatic Approach Exploiting Machine Learning. Remote Sensing. 2021; 13(3):461. https://doi.org/10.3390/rs13030461

Day M. (2021) BIM and the Notre-Dame resurrection. AEC Magazine // https://aecmag.com/features/bim-and-the-notredame-resurrection-revit/

Martín-Lerones P, Olmedo D, López-Vidal A, Gómez-GarcíaBermejo J, Zalama E. BIM Supported Surveying and Imaging Combination for Heritage Conservation. Remote Sensing. 2021; 13(8):1584. https://doi.org/10.3390/rs13081584

López, F.L., Lerones, P.M., Llamas J., Gómez-García-Bermejo J., and Zalama E. (2018) A Review of Heritage Building Information Modeling (H-BIM). Multimodal Technol. Interact. 2018, 2(2), 21; https://doi.org/10.3390/mti2020021

Pepe M., Costantino D., Alfio V.S., Restuccia A.G., Papalino N.M. (2021). Scan to BIM for the digital management and representation in 3D GIS environment of cultural heritage site, Journal of Cultural Heritage, Volume 50, 2021, Pages 115-125, ISSN 1296-2074, https://doi.org/10.1016/j.culher.2021.05.006.

Schevers, Hans \& Mitchell, John \& Akhurst, Paul \& Marchant, David \& Bull, Stuart \& McDonald, Kevin \& Drogemuller, Robin \& Linning, Chris. (2007). Towards digital facility modelling for Sydney Opera House using IFC and semantic web technology. Journal of Information Technology in Construction. 12.

Standards USA (2014) National BIM standard: version 2. US National BIM Standards Committee (NBIMS). https://www.nationalbimstandard.org/

Tobiáš P. (2016). BIM, GIS and semantic models of cultural heritage buildings. Geoinformatics FCE CTU 15(2), 2016, doi:10.14311/gi.15.2.3

Volk, R.; Stengel, J.; Schultmann, F. (2014): Building Information Models (BIM) for existing buildings - literature review and future needs - Automation in Construction 38, pp.109-127, DOI: 10.1016/j.autcon.2013.10.023. 